\title{
Acrocomia aculeata (JACQ.) LODD. EX MART.: ASPECTOS ECOLÓGICOS, USOS E POTENCIALIDADES
}

\author{
Acrocomia aculeata (JACQ.) LODD. EX MART.: ECOLOGICAL ASPECTS, \\ USES AND POTENTIALITIES \\ LORENZI, G. M. A. C. ${ }^{1}$; NEGRELLE, R. R. B. ${ }^{2}$ \\ RECEBIDO: 09/08/06 ACEITE: 12/06/06
}

\section{INTRODUÇÃO}

A palmeira bocaiúva (Acrocomia aculeata (Jacq.) Lodd. ex Mart.) é espécie nativa das florestas tropicais, cuja principal característica é a presença de espinhos escuros, longos e pontiagudos na região dos nós.

Tradicionalmente, no Pantanal Mato-grossense, a comunidade utiliza no âmbito doméstico suas folhas, frutos e sementes para diversos fins. Em outras regiões brasileiras já estão sendo comercializados, de forma incipiente, produtos derivados desta palmeira. Considerando a importância sócio-ambiental desta espécie no contexto do Pantanal Mato-grossense elaborou-se esta pesquisa, de cunho exploratório descritivo, com o objetivo de gerar informações botânicas, ecológicas e etnobotânicas que possam subsidiar o extrativismo sustentável desta espécie.

\subsection{DESENVOLVIMENTO DO TEMA}

\subsubsection{Histórico}

A família Arecaceae, anteriormente denominada Palmae, é constituída por um grupo de espécies genericamente conhecidas como palmeiras. A palavra palma é de origem remota. Os povos itálicos aplicavam-na à tamareira (Phoenix dactilifera L.) da África Mediterrânea e do Oriente Médio. Os gregos chamavam-na fóinix, palavra de origem fenícia (Lorenzi et al., 1996).

\footnotetext{
${ }^{1}$ Doutora em Agronomia, pesquisadiora associada do Lab. Oikos, Departamento de Botânica da Universidade Federal do Paraná. gmlorenzi@uol.com.br

${ }^{2}$ Doutora em Ecologia e Recursos Naturais, Professoa Adjunta do Departamento de Botânica da Universidade Federal do Paraná. negrelle@ufpr.br
} 
As palmeiras são consideradas as aristocratas do reino vegetal, sendo denominadas pelos botânicos de "Príncipes das florestas", dado o porte altaneiro e elegante que as distingue facilmente de outras plantas (Bondar, 1964, Lorenzi et al., 1996).

Esta família inclui representantes dióicos e monóicos, de morfologia variada. As raízes podem ser subterrâneas ou aéreas. Os estipes podem ser solitários ou cespitosos e raramente escandentes, aéreos ou subterrâneos. Quando aéreo, o estipe pode apresentar-se liso ou densamente coberto por espinhos. As folhas tanto curtas como longas apresentam-se de forma palmada, pinadas e inteiras com bainhas abertas ou fechadas e pecíolos curtos ou longos. As inflorescências interfoliares ou infrafoliares na antese, apresentam-se em forma de espiga, com presença de poucas ou muitas ráquilas. As flores são geralmente trímeras. Os frutos podem ser tanto pequenos como muito grandes com o pericarpo liso ou com presença de espinhos. O tegumento da semente é duro e contém no seu interior uma ou mais sementes. As plântulas possuem folhas inteiras, bífidas e pinadas (Miranda et al., 2001).

Dados paleontológicos indicam que as palmeiras surgiram no período Paleozóico Superior, provavelmente a partir de um grupo de fetos com sementes. Contudo, vieram a se diferenciar melhor na era Geológica Secundária ou Mesozóica, no Período Cretáceo Superior e início da Era Cenozóica. Registros históricos constatam a ocorrência de mais de 80 espécies de palmeiras fósseis. Destas, são existentes até hoje: Astrocaryum, Cocos, Geonoma, Manicaria, Nipa, Phoenix, Sabal e Thrinax. As restantes são protótipos dos gêneros atuais (Bondar, 1964; Alves; Demattê, 1987).

Palmeiras que hoje são limitadas às regiões da Ásia Tropical ocorriam na Europa Ocidental formando densos e luxuriantes bosques no atual território da Finlândia, Rússia, Alemanha, Ásia, África e Américas (Bondar, 1964).

Diversas espécies ainda são encontradas fora das regiões subtropicais e são de grande interesse para o paisagismo das regiões temperadas, onde o uso de palmeiras é muito restrito. Entre as mais tolerantes ao frio cita-se: Sabal palmetto (Walter) Lodd. ex Schult. \& Schult.; Washingtonia filifera (Lind.) Wendl. e W. Robusta 
H. Wendl., Trachycarpus fortunei (Hook.) Wendl., Nannorrhops ritchieana (Griff.) Aitch., Chamaerops humilis L., Butia spp., Jubaea chilensis (Mol.) Baillon, Ceroxylon andnum , Rhopalostylis sapida H. Wendl. e Drude (Lorenzi et al., 1996).

Atualmente, registra-se a existência de aproximadamente 200 gêneros e 1500 espécies de palmeiras no mundo com distribuição pantropical. Os limites extremos de distribuição são $44^{\circ} \mathrm{N}$ (Europa) com ocorrência de Chamaerops humilis L., e $44^{\circ} \mathrm{S}$ (Nova Zelândia) com ocorrência de Rhopalostylis sapida H.A.Wendl. e Drude. A maior concentração de espécies está na região da linha do Equador. Nas Américas, com exceção de Bactris, Geonoma, Chamaedorea, Acrocomia, Euterpe, Prestoea e Desmoncus que possuem distribuição ampla, os demais gêneros são, naturalmente, restritos a uma determinada área com característica geológica, topográfica, climática específicas (Henderson et al.; 1995).

No Brasil, Martius (1824) descreveu:

"abundam na terra brasilica, medra nas areias do litoral, crescem nas campinas infindas, levantam-se destemidas e orgulhosas nos paués e brejos, expandem sobanceiras suas lindas frondes por entre o verdume das florestas e vivem mesmo no ressequido solo das caatingas, lugares em que apenas cardos e faveleiras logram manter existência. Grandes ou pequenas surgem em toda parte, nas praias sobre os cômores, na encarpa das rochas, no solo fértil e no estéril."

Segundo Glassman (1972), o Brasil conta com cerca de 500 espécies nativas de palmeiras. Destas, na região do Brasil Central e áreas adjacentes são encontrados cerca de 11 gêneros e 44 espécies, sendo que Trithrinax é endêmica, Syagrus e Butia têm ampla distribuição assim como as espécies de Attalea, Allagoptera e Acrocomia que são comuns na região (Henderson et al., 1995).

O gênero Acrocomia é composto por duas espécies - aculeata (Jacq.) Lodd. ex Mart. e A. hassleri (B. Rodr.) W. J. Hahn - que diferem basicamente no tamanho dos indivíduos, sendo a primeira de maior porte. A. aculeata é amplamente distribuída nas regiões secas da América Tropical e $A$. hassleri é restrita à região de cerrado no Brasil e Paraguai (Henderson et al., 1995). O termo Acrocomia deriva do grego "Akron" (uma) 
e "Kome" (cabeleira) sugerindo que as folhas estão dispostas no formato de uma coroa (Novaes, 1952; Henderson et al., 1995).

\section{CLASSIFICAÇÃO BOTÂNIICA}

Acrocomia aculeata foi primeiramente descrita por Jacquin ${ }^{3}$ em 1763 tendo como basinômio Cocos aculeatus Jacq.. Em 1824, foi inserida por Martius no gênero Acrocomia, sendo designada como Acrocomia sclerocarpa. Posteriormente, em 1845, Loddiges $^{4}$ coloca ambos em sinonímia, designando-a como Acrocomia aculeata (Missouri, 2005).

Em termos taxonômicos, Acrocomia aculeata (Jacq.) Lodd. ex Mart. (Figura 1) está categorizada em APG II $2003^{5}$ (Souza; Lorenzi, 2005):

Angiospermae

Monocotiledoneae

Commelinidae

Arecales Bromhead (1840)

Arecaceae Schultz-Schultzenstein (1832), nom. cons.

Acrocomia Mart., 1824

Acrocomia aculeata (Jacq.) Lodd. ex Mart ${ }^{6}$.

3 JACQUIN, N . J. von. Selectarum Stirpium Americanarum Historia 278, t. 169. 1763 Disponível em <http://www.mobot.mobot.org/cgi-bin/search> Acesso em 16 set 2004

${ }^{4}$ LODDIGES Historia Naturalis Palmarum v.3, n.8, 286p, 1845 Disponível em $<$ http://www.mobot.mobot.org/cgi-bin/search> Acessado em 16 set 2004

${ }_{6}^{5}$ Angiosperm Phylogeny Group

${ }^{6}$ MARTIUS, k. F. P. Historia Naturalis Palmarum, v.2, p.. 285-286, 1824. 
Figura 1: Acrocomia aculeata (Jacq.) Lodd. ex Mart. (Bocaiúva) na RPPN SESC Pantanal, mun Barão de Melgaço/ MT, $56^{\circ}$ a $57^{\circ} \mathrm{W}$ e $16^{\circ}$ a $17^{\circ} \mathrm{S}$ (Foto: G. Lorenzi, nov/2002).

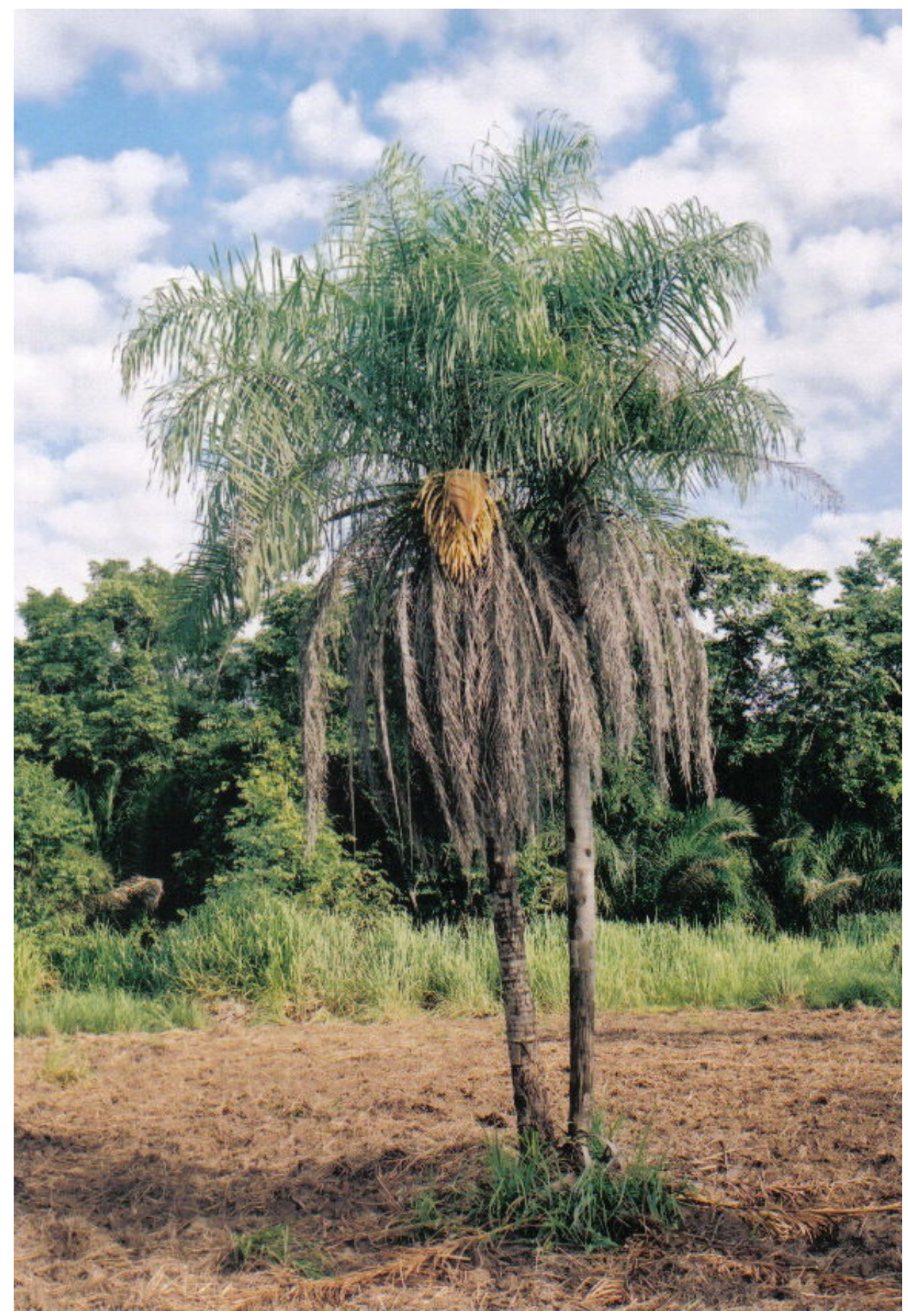


Acrocomia aculeata (Jacq.) Lodd. ex Mart. apresenta as seguintes sinonímias (Henderson et al., 1995):

Acrocomia antiguana L.H. Bailey

Acrocomia antioquensis Posada-Arango

Acrocomia belizensis L.H. Bailey

Acrocomia christopherensis L.H. Bailey

Acrocomia chunta Covas \& Ragonese

Acrocomia erisacantha Barb. Rodr.

Acrocomia fusiformis Sweet

Acrocomia glaucophylla Drude

Acrocomia grenadana L.H. Bailey

Acrocomia hospes L.H. Bailey

Acrocomia ierensis L.H. Bailey

Acrocomia intumescens Drude

Acrocomia karukerana L.H. Bailey

Acrocomia lasiospatha Mart.

Acrocomia media O.F. Cook

Acrocomia mexicana Karw. ex Mart.

Acrocomia microcarpa Barb. Rodr.

Acrocomia mokayayba Barb. Rodr.

Acrocomia odorata Barb. Rodr.

Acrocomia panamensis L.H. Bailey

Acrocomia pilosa León

Acrocomia quisqueyana L.H. Bailey

Acrocomia sclerocarpa Mart.

Acrocomia sclerocarpa var. wallaceana Drude

Acrocomia spinosa (Mill.) H.E. Moore

Acrocomia subinermis León ex L.H. Bailey

Acrocomia totai Mart.

Acrocomia ulei Dammer 
Acrocomia viegasii L.H. Bailey

Acrocomia vinifera Oerst.

Acrocomia wallaceana (Drude) Becc.

Bactris globosa Gaertn.

Cocos aculeatus Jacq.

Cocos fusiformis Sw.

Palma spinosa Mill.

O nome vulgar ou popular varia de acordo com a região de distribuição desta espécie: Mbocayá (Argentina); totaí (Bolivia); corozo (Colombia, Venezuela); tamaco (Colombia); coyol (Costa Rica, Honduras, Mexico); corosse (Haiti). Também registramse como nomes populares desta espécie: macaw palm, macaya, groo groo, grugru palm, corosse, mbocayá, cobrush, coquito, mocayá, catey, cayara, cayiete, ocori, palma de vino, gri-gri, mucajá, grou grou (Missouri, 2005; Ecocrop, 2005; Fruits, 2005).

No Brasil, é conhecida por bocaiúva, chiclete-de-baiano, coco-baboso, coco-decatarro, coco-de-espinho, macacauba, macaiba, macaibeira, macajuba, macaúba, macaúva, mucaia, mucaja e mucajaba (Texeira, 1996: Fruits, 2005).

A denominação "mbocayá" deriva das palavras indígenas "mboka" (que se quebra estalando) e "ya" ou "já" (fruto), indicando árvore de frutos que estalam (Novaes, 1952).

\subsection{DESCRIÇÃO GERAL}

Acrocomia aculeata é uma palmeira nativa das florestas tropicais cujo estipe atinge de 10 a $15 \mathrm{~m}$ de altura e 20 a $30 \mathrm{~cm}$ de diâmetro. A região dos nós é coberta de espinhos escuros, pontiagudos com cerca de $10 \mathrm{~cm}$ de comprimento. Frequentemente, o estipe é coberto pelas bases dos pecíolos, que permanecem aderidas a este por muitos anos. As folhas verdes, ordenadas em diferentes planos dando um aspecto plumoso à copa, são pinadas com comprimento variando de 4 a $5 \mathrm{~m}$, apresentando aproximadamente 130 folíolos de cada lado e espinhos na região central (Arboles, 2005; Missouri, 2005; Fruits, 2005; Grupo, 2005; Miranda et al., 2001; Lorenzi et al., 1996, Texeira, 1996). 
Entre as folhas destacam-se a espata de até $2 \mathrm{~m}$ comprimento, as inflorescências amarelas e os cachos de frutos de tom marrom-amarelado. A inflorescência é em espádice, com 50 a $80 \mathrm{~cm}$ de comprimento, pendente, protegida por espata de acúleos castanhos. As flores de coloração amarelo-claro são unissexuais e ambos os sexos aparecem numa mesma inflorescência. As flores femininas nascem na base da inflorescência e as masculinas no topo. Os frutos são esféricos ou ligeiramene achatados, em forma de drupa globosa com diâmetro variando de 2,5 a 5,0 $\mathrm{cm}$. O epicarpo rompe-se facilmente quando maduro. O mesocarpo é fibroso, mucilaginoso, de sabor adocicado, rico em glicerídeos, de coloração amarelo ou esbranquiçado, comestível. O endocarpo é fortemente aderido à polpa (mesocarpo), com parede óssea enegrecida e a amêndoa oleaginosa, comestível e revestida de uma fina camada de tegumento. Cada fruto contém, geralmente, uma semente envolvida por endocarpo duro e escuro com aproximadamente $3 \mathrm{~mm}$ de espessura (Gray, 2005; Fruits, 2005; Henderson et al., 1995; Silva, 1994; Bondar, 1964).

A frutificação ocorre durante todo o ano e o frutos amadurecem, principalmente, entre setembro e janeiro (Lorenzi, 2006). Os principais polinizadores são coleópteros das famílias Curculionidae, Nitidulidae e Escarabaeidae. A inflorescência é visitada pelas abelhas do grupo Trigonia, que coletam o pólen das flores masculinas e polinizam as flores femininas (Henderson et al., 1995; Scariot, 1998).

\subsubsection{EXIGÊNCIAS AMBIENTAIS}

Em condições naturais, as sementes podem levar de um a dois anos para germinar. No entanto, quando submetidas a escarificação e acondicionadas a temperatura superior a $35{ }^{\circ} \mathrm{C}$ podem germinar entre quatro e seis meses. As plântulas apresentam crescimento lento (Gray, 2005; Rarepalmseed, 2005).

Esta palmeira tem forte interação com a fauna, seus frutos integram a dieta de araras, capivaras, antas, emas entre outros animais, os quais são os dispersores das sementes (Pott; Pott, 1994). 
Acrocomia aculeata habita áreas abertas e com alta incidência solar, adapta-se a solos arenosos e com baixo índice hídrico. Porém, desenvolve-se melhor em locais onde há solos férteis (Gray, 2005; Missouri, 2005).

\subsubsection{DISTRIBUIÇÃO}

Com ampla distribuição geográfica, ocorre em todo o Trópico Americano, do México a Argentina, Bolívia, Paraguai, Antilhas, exceto Equador e Peru. Preferencialmente, em regiões com estação chuvosa bem definida e de baixas altitudes. No entanto, há registros de sua ocorrência nos Andes Colombianos cuja altitude é de 1200 m s.n.m.. Sua área de distribuição tem sido fortemente influenciada pelas atividades humanas. Na Costa Rica, foi introduzida pelos índios na época précolombiana, no México e América Central pelos maias (Arboles, 2005; Missouri, 2005; Henderson et al., 1995).

No Brasil, é considerada como a palmeira de maior dispersão, com ocorrência de povoamentos naturais desta espécie em quase todo território. Entretanto, as maiores concentrações estão localizadas em Minas Gerais, Goiás, Mato Grosso e Mato Grosso do Sul, sendo amplamente espalhada pelas áreas de Cerrado (Bondar, 1964; Silva, 1994; Henderson et al., 1995). No passado, ela ocorria em abundância também em São Paulo, mas as populações naturais foram sistematicamente substituídas pelo cultivo do café (Novaes, 1952)..

\section{USOS E POTENCIALIDADES}

No âmbito de levantamento etnobotânico realizado na região do Pantanal Matogrossense por Lorenzi (2006) diferentes categorias de uso foram identificadas como associadas às distintas partes do corpo vegetal de $A$. aculeata sendo: 1) madeira para produção de mourões e estacas; 2) o estipe para obtenção do palmito e da seiva utilizados, respectivamente, como alimento e bebida; 3) as folhas para forragem animal, cobertura de casa e extração de fibras usadas no fabrico de linha de pesca e redes; 4) os espinhos como substituto de agulha para cozer; 5) os frutos como alimento in natura, 
para obtenção da polpa com a qual é preparado um fortificante para pneumonia, sorvetes e licor ou, ainda, para extração do óleo que é utilizado como óleo de cozinha, hidratante capilar e combustível para geração de energia; 6 ) a semente parte lignificada como substituto da brita no concreto e confecção de botões e a amêndoa como alimento (coquinho) e no preparo de paçoca (coquinho triturado mais farinha de mandioca) e, também, para extração do óleo o qual é utilizado tanto como alimento,como combustível como com fins cosméticos. Vários destes usos foram referenciados como registro histórico e para outros registrou-se a revitalização de certos usos, em função principalmente do apelo turístico (ver Lorenzi, 2006)

A quase totalidade das utilidades da bocaiúva registradas no levantamento realizado por Lorenzi (2006) é coincidente com as citadas em outros trabalhos (ver por exemplo Pott e Pott, 1994; Henderson et al., 1995; Almeida et al., 1996; Lorenzi et al., 1996; Miranda et al., 2001; Arboles, 2005; Globo Rural, 2005; Fruits, 2005; Gray, 2005; Ecocorp, 2005; Salis e Juracy, 2005).

\section{REFERÊNCIAS}

ALVES, M. R. P.; DEMATTÊ, M. E. S. P. Palmeiras: características botânicas e evolução. Campinas: Fundação Cargill, 1987. 129p.

ARBOLES del area del canal de Panamá Acrocomia aculeata (Jacq.) Lodd. ex Mart. Disponível em:<http://www.ctfs.si.edu/webatlas/spanish/acropa.html> Acesso em: 18 jul. 2005.

BONDAR, G. Palmeiras do Brasil. São Paulo: Instituto de Botânica, São Paulo, 1964. n.2; p. $50-554$

ECOCROP Acrocomia aculeata. Disponível em:<http.//ecotrop.fao.org $>$ Acesso em: 12 nov. 2005.

FRUITS from America: an ethnobotanical inventory Acrocomia aculeata. Disponível em: $<$ http://www.ciat.cgiar.org/ipgri/fruits from americas/frutales/Acrocomiaaculeata.htm $>$ Acesso em: 8 set. 2005. 
GLASSMAN, S.F. A revision of B.E. Dahlgren's index of American palms. Lehre: J. Cramer, 1972.

GLOBO RURAL. 0 tesouro escondido. Disponível em: <http://www.globoruraltv.globo.com/GRural>. Acesso em: 19 dez. 2005

GRAY, M. Palm and Cycad Societies of Australia. Disponível em: <http://www.pacsoa.org.au/palms/Acrocomia/aculeata.html> Acesso em: 20 set. 2005.

GRUPO verde Acrocomia aculeata . Disponível em: http://www.grupoverdepalms.com/index2.html> Acesso em 12 nov. 2005.

HENDERSON, A.; GALEANO, G.; BERNAL, R. Field Guide to the Palms of the Americas New Jersey: Princepton University, 1995. p.166-167.

LORENZI, G. M. A. C. Acrocomia aculeata (Lodd. ) ex Mart. - ARECACEAE: BASES PARA O EXTRATIVISMO SUSTENTÁVEL. Curitiba: 2006, 172f. Tese. Programa de Pós-graduação em Agronomia, Universidade Federal do Paraná.

LORENZI, H.; SOUZA, H. M.; MEDEIROS-COSTA, J. T.; CERQUEIRA, L. S. C.; BEHR, N. Palmeiras do Brasil: exóticas e nativas. Nova Odessa: Editora Plantarum, 1996. p. $1-20$

MARTIUS, K. F. P. Historia Naturalis Palmarum. Leipzig: T. O. Weigel, 1824. v..2; p. 285-286

MIRANDA, I.P.A.; RABELO, A.; BUENO, C. R.; BARBOSA, E. M.; RIBEIRO, M. N. S. Frutos de Palmeiras da Amazônia. Manaus: MCT INPA, 2001. p. 7-10

MISSOURI BOTANICAL GARDEN. Acrocomia aculeata Disponível em: <http.//www.mobot.mobot.org/cgi-bin/search> Acesso em: 16 out. 2005.

NOVAES, R. F. Contribuição para o estudo do coco macaúba. Piracicaba, 1952, 85 f. Tese (Doutorado em Ciências Agrárias) Escola Superior de Agricultura "Eça de Queiroz da Univeersidade de São Paulo, Piracicaba.

POTT, A.; POTT, V.J. Plantas do Pantanal. Corumbá: Embrapa Pantanal,1994. 320p.

RAREPALMSEEDS Acrocomia aculeata Disponível em: <http://www.rarepalmseeds.com/pix/AcrAcu.shtml>. Acesso em: 10 out. 2005

SALIS, S. M.; JUARACY, A. R. da M. A utilização da bocaiúva no Pantanal. Disponível em: <htpp.//www. portaldoagronegocio.com.br> Acesso em: 16 dez. 2005. 
SCARIOT, A. Seed dispersal and predation of the palm Acrocomia aculeata. Principes, Brasília, v.42, n.1, p.5-8, 1998.

SILVA, J.C. Macaúba: fonte de matéria prima para os setores alimentíceo, energético e industrial. Viçosa: CEDAF/DEF/UFV, 1994. 41 p.

TEIXEIRA, E. Acrocomia aculeata In: TASSARO, H. Frutas no Brasil. São Paulo: Empresa das Artes, 1996, p.15. 